\title{
De 4-tot-10 verwacht niveau-schaal (410VN-schaal) bij persoonlijke beoordelingen
}

\author{
Th.J. ten Cate, E.W.M.T. ter Braak, J. Frenkel, A.C. van de Pol
}

\section{Samenvatting}

Sinds 2004 wordt in het UMC Utrecht een relatieve 4-tot-10 puntsschaal (410VN-schaal) gebruikt bij persoonlijke beoordelingen van semiartsen, onder meer bij korte klinische beoordelingen. De schaal biedt voordelen boven andere schalen. De methode gaat uit van drie beoordelingscategorieën: onder verwacht niveau (waarden 4 en 5), op verwacht niveau (waarden 6, 7 en 8) en boven verwacht niveau (waarden 9 en 10). Het uitgangspunt is dat zonder nadere informatie de te beoordelen student een middenwaarde verdient op het 'verwachte niveau', d.w.z. een 7. Hiervan wordt afgeweken als bij observatie blijkt dat deze waarde voor de student te hoog of te laag is. De achtergronden en het gebruik van de schaal worden beschreven. De eerste ervaringen met het gebruik van deze schaal bij beoordelingen van semiartsen in vergelijking met coassistenten van een oud curriculum zijn gunstig. (Cate ThJ ten, Braak EWMT ter, Frenkel J, Pol AC van de. De 4-tot-10 verwacht niveau-schaal (410VN-schaal) bij persoonlijke beoordelingen. Tijdschrift voor Medisch Onderwijs 2006;25(4):157-163.)

\section{Inleiding}

Er is een toename van persoonlijke beoordelingen in het medisch onderwijs, vanuit de behoefte om kwaliteiten te beoordelen die niet goed met een schriftelijke toetsing meetbaar zijn. Bij deze beoordelingen moet een docent een student of diens prestatie beoordelen op grond van eigen observatie. Ze dwingen de docent om, in tegenstelling tot schriftelijke toetsen, per geval een inschatting te maken van wat de student weet, kan of heeft gepresteerd. Daarbij speelt het subjectieve oordeel een belangrijke rol. Niet alleen de student varieert, maar ook de beoordelaar. Er is in deze situaties behoefte aan houvast om een redelijk oordeel te kunnen vellen.

Er zijn veel methoden en schalen in omloop voor de individuele boordeling van studenten, coassistenten en assistenten in opleiding. Veelgebruikte schalen zijn rapportcijfers, schalen met vijf waarden (vaak 1-2-3-4-5), drie of vier waarden (1-2-3 of $0-1-2-3$ ), twee waarden (onvoldoende/voldoende) of de in het buitenland gangbare letters (ABCDF). Er is nogal eens discussie over de manier waarop deze schalen moeten worden ingevuld. Twee veelgehoorde kwesties zijn dat (a) docenten het moeilijk vinden om oordelen te geven en (b) de neiging bestaat om relatief hoge scores te geven.

Persoonlijke beoordelingen zijn lastig, omdat een sterk appèl wordt gedaan op een subjectief oordeel. Weet de beoordelaar weinig van de kandidaat, dan wordt het oordeel al snel een gok. Dan ontstaat soms de neiging om één grote cirkel om dezelfde scores voor diverse aspecten te trekken. Dat is uiteraard geen nauwkeurige weergave van de geobserveerde sterke en zwakke punten. In psychometrische termen: de betrouwbaarheid van zulke boordelingen is gering.

De scores die zo worden vastgelegd zijn ook vaak te hoog. De oorzaak daarvan is goed te begrijpen. Een docent die aarzelt over een beoordeling en moet afgaan op eigen observaties of op incomplete informatie zal zelden te lage scores geven en vaak - voor de zekerheid - naar boven afron- 
den. Dan wordt er in ieder geval geen fout gemaakt ten nadele van de student. Er is, met andere woorden, een opwaartse druk bij dergelijke beoordelingen en die komt van twee kanten. De student wil graag een hoog cijfer hebben, de docent scoort liever te hoog dan te laag. Je maakt nu eenmaal liever vrienden dan vijanden. Bij te lage scores is niet alleen de student teleurgesteld, maar de docent haalt zich ook extra werk op de hals als er een oplossing zoals een herkansing geregeld moet worden, en bij externe evaluaties leiden te lage cijfers vaak eerder tot kritiek op de docent dan te hoge cijfers. Dat alles leidt tot een wijdverbreide gewoonte om te hoge cijfers te geven bij persoonlijke beoordelingen. ${ }^{1}$

Hier raken kandidaten aan gewend, en de norm van wat 'voldoende' is verschuift. Een 6 verliest haar oorspronkelijke betekenis en velen zijn pas tevreden met een 8. Daar komt bij dat de vergelijkbaarheid van scores tussen kandidaten belangrijker wordt dan de vergelijking met een absolute norm. Al met al is er dus niet alleen een betrouwbaarheidsprobleem maar ook een validiteitsprobleem.

De docent moet een sterk normbesef en een groot verantwoordelijkheidsgevoel hebben om lage cijfers te geven als dat nodig is. Dat men dat niet altijd opbrengt is docenten niet erg te verwijten, maar het vormt wel een probleem. Albanese heeft enkele jaren geleden terecht gewaarschuwd voor een dreigende erosie van de kwaliteit van de opleiding bij het toenemend gebruik van dit soort beoordelingen. ${ }^{1}$ De praktijk is echter dat juist steeds vaker authentieke werksituaties in de beoordeling worden betrokken. ${ }^{2}$ We zien dan ook een toename van persoonlijke beoordelingen in de kliniek, vanuit de terechte wens om competenties in de praktijk te observeren en te objectiveren. ${ }^{3-4}$ Het is dan goed om methodes en beoordelingsschalen te kiezen die zoveel mogelijk de docent ondersteunen in het consistent oordelen met redelijke normen. In 2004 hebben wij een zogeheten '4-tot-10 verwacht niveau-schaal' (410VN-schaal) ontwikkeld, die wordt ingezet bij klinische beoordelingen van semiartsen in het zesde studiejaar van de opleiding genees $\neg$ kunde in de Universiteit Utrecht, en die beoogt deze ondersteuning bij een consistente beoordeling enigszins te bieden.

\section{De 410VN-schaal}

Met de 410VN-schaal wordt een schaal bedoeld zoals in tabel 1. Kenmerkend zijn de becijfering van 4 tot 10 en de relatering aan een 'verwacht niveau' in plaats van aan een absolute standaard. In essentie is de schaal een combinatie van een 3-puntsschaal met een 10-puntsschaal.

\section{'Verwacht niveau'}

Bij persoonlijke beoordelingen moet de beoordelaar een zo goed mogelijke schatting geven van het geobserveerde niveau van het handelen van de kandidaat. De logische eerste opwelling is om het eindniveau van de opleiding als maatstaf te nemen. Als de kandidaat een aios is, zou het referentieniveau dat van de medisch specialist bij de voltooiing van de opleiding kunnen zijn. Dat betekent echter dat de beginnende assistent steeds onvoldoende scores zal krijgen. Dat is om twee redenen niet gewenst: (a) veelvuldige 'onvoldoen-

Tabel 1. De 410VN-schaal.

\begin{tabular}{c|ccc|cc}
\hline \multicolumn{2}{c}{$\begin{array}{c}\text { Beneden het } \\
\text { verwachte niveau }\end{array}$} & $\begin{array}{c}\text { Op het } \\
\text { verwachte niveau }\end{array}$ & \multicolumn{1}{c}{$\begin{array}{c}\text { Boven het } \\
\text { verwachte niveau }\end{array}$} \\
\hline 4 & 5 & 6 & 7 & 8 & 9 \\
\hline
\end{tabular}


des' botsen met de gewenste didactiek, omdat daar geen opbouwende en stimulerende werking van uitgaat en (b) supervisoren zijn meestal niet goed in staat en bereid dit te doen. Studenten of aios die het relatief goed doen wil men (terecht) graag belonen met een goed cijfer, ongeacht de fase van het opleidingstraject.

De vraag is nu: wat is dan het verwachte niveau? Het verwachte niveau van respectievelijk een coassistent, een tweedejaars assistent en een jonge specialist wordt bepaald door ervaren opleiders uit de eigen beroepsgroep. Er zijn aanwijzingen voor te geven, maar in laatste instantie bepaalt de ervaren klinisch docent in het vakgebied wat het verwachte niveau is. Dat vereist dus ervaring. Voor iedere beoordeling waarvoor een expertoordeel nodig is, vergen de normen een 'oog van de meester'.

Dat mag onbevredigend klinken, maar er is geen betere oplossing voor de normstelling dan overleg onder experts en ervaring met kandidaten van de diverse niveaus. Voor nieuwe beoordelaars is het nuttig om eerst enkele malen met een ervaren beoordelaar mee te doen. Ook is het nuttig om met een groep supervisoren af en toe eens tijd te besteden aan het gezamenlijk observeren van een videofragment van een arts-patiëntcontact, dan beoordelingen uit te voeren en vervolgens de gegeven scores met elkaar te vergelijken. De ervaring leert dat dit zeer waardevolle discussies oplevert over zowel beoordelingsnormen als ook over de gewenste uitvoering van klinische handelingen waarover soms minder overeenstemming bestaat dan men zou denken. 5

\section{Aanwijzingen voor de scoring met de 410VN-schaal in de praktijk}

Zoals gezegd staat inhoudelijke expertise en ervaring voorop bij het scoren van prestaties van kandidaten. Daarnaast is het echter nuttig om enkele algemene aanwij- zingen voor de interpretatie van cijfers te geven die passen bij de 410VN-schaal:

1. In de $410 \mathrm{VN}$-schaal vormt de middenwaarde van het verwachte niveau (de 7) het centrale referentiepunt. Ga er in beginsel altijd van uit dat de student of assistent, zonder nadere informatie, een centrale score op het verwachte niveau verdient. De beoordeling van de student wordt vervolgens gevormd door de mate van afwijking van dit referentiepunt, naar beneden of naar boven.

2. De ruime meerderheid van de scores (ca. 75\%) wordt binnen het verwachte niveau gegeven. Hiermee worden aan de studenten beperkte signalen gegeven: er hoeft niets te verbeteren, omdat het niveau relatief goed is (8); of: hier zou verbetering kunnen plaatsvinden (6).

3. Sterke signalen vormen de 5 en de 9 . Een 5 betekent: hier moet verbetering gaan plaatsvinden; dit moet volgende keer beter; schenk hier aandacht aan; probeer te oefenen; vergaar meer kennis op dit terrein, e.d. Een 9 betekent: je stijgt duidelijk uit boven de groep; je verdient een compliment dat aan de meeste studenten niet wordt gegeven.

4. De scores 4 en 10 vormen zeldzaamheden. De 4 is een 'rode kaart': er moet remediërende actie plaatsvinden. Een 4 is niet compatibel met een voldoende eindoordeel, c.q. kan niet gecompenseerd worden. De 10 is zo uitzonderlijk dat slechts weinigen dit ooit toegekend krijgen.

Het effect van de scores voor het leerproces wordt sterk vergroot als de observatie direct gevolgd wordt door een mondelinge uitleg en specifieke feedback over de geobserveerde handelingen. Deze schaal kan daarbij helpen als de afspraak geldt dat waarden buiten het verwachte niveau gemotiveerd moeten worden. Door coassistenten en aios wordt dergelijke feedback als uiterst nuttig ervaren. 


\section{Rekenen met de 410VN-schaal}

De $410 \mathrm{VN}$-schaal sluit weliswaar aan bij het rapportcijfersysteem, maar enkele rekenkundige kanttekeningen zijn op hun plaats. De schaal is in zijn opzet in categorieën niet goed als lineair te beschouwen. De schaal is de combinatie van een 3-puntsschaal met een 10-puntsschaal. Men beoordeelt de kandidaat primair als 'op verwacht niveau', 'onder verwacht niveau' of 'boven verwacht niveau'. De cijfers vormen specificeringen, omdat een 3-puntsschaal in de praktijk te weinig differentieert. Er wordt bij de overgangen tussen 'onder' en 'op' en tussen 'op' en 'boven' echt een grens overschreden, waarvoor ook een aanvullende argumentering van de beoordelaar en een vorm van actie op hun plaats zijn. Dat maakt dat de afstanden tussen 5 en 6 en tussen 8 en 9 een andere betekenis hebben dan die tussen 6 , 7 en 8. Dit kan ook visueel ondersteund worden als de afstanden tussen 5 en 6 en tussen 8 en 9 op het formulier relatief groot zijn of als er een verticale lijn tussen loopt (zie tabel 1).

Veel beoordelingsformulieren bevatten meerdere aspecten waarop een score wordt gegeven. De neiging bestaat dan om de scores op te tellen en te delen door het aantal om op een nauwkeurig gemiddeld eindoordeel uit te komen. Deze nauwkeurigheid is schijn, omdat niet alle beoordeelde aspecten even zwaar hoeven te wegen. Sommige onderdelen van het formulier kunnen belangrijker zijn dan andere.Daarom is het verstandig om aan een beoordelingsformulier met meerdere items ook een afzonderlijk globaal oordeel toe te voegen. Verschillen in weging kunnen dan meegenomen worden en men kan ook aspecten laten meewegen die niet goed door de afzonderlijke items gedekt worden. Ten slotte is het bekend dat globale oordelen nogal eens betrouwbaarder zijn dan gedetailleerde checklists. ${ }^{6}$ Het is wel verstandig om een algemeen oordeel dat afwijkt van het gemiddelde van de overige items te voorzien van een toelichting.

Een berekening die wel kan worden gemaakt met de scores is een gemiddelde score over meerdere beoordelingsmomenten bij dezelfde persoon op hetzelfde item. De resulterende score op dat item is dan betrouwbaarder dan elk van de afzonderlijke scores. Voor de KKB (korte klinische beoordeling), c.q. de mini-CEX (mini-clinical examination exercise) wordt aanbevolen om vier tot veertien observaties te verrichten om tot een betrouwbare uitspraak over de vaardigheid van een kandidaat te komen. ${ }^{7}$

Voor het bepalen van een grens voor zakken en slagen bij eindoordelen moeten afspraken worden gemaakt per domein waarover geoordeeld wordt. Betreft het zeven items over professioneel gedrag, dan zou men bijvoorbeeld kunnen afspreken dat er een voldoende eindoordeel moet zijn en dat er geen score 4 en niet meer dan één score 5 mag zijn om te kunnen slagen. Voor andere domeinen kunnen andere afspraken gelden.

\section{Ervaringen met de 410VN-schaal}

De 410VN-schaal is in het studiejaar 20042005 in de Utrechtse medische opleiding toegepast bij beoordelingen in het zesde studiejaar van het nieuwe curriculum. De scores zijn vergeleken met de scores die in het laatste studiejaar zijn gegeven aan studenten in een oud curriculum. In 20042005 zijn zowel studenten die behoren tot de laatste groepen van het oude curriculum als de eerste studenten van het nieuwe curriculum afgestudeerd.

\section{Methode}

De gegevens zijn verzameld in november 2005. Alle ontvangen eindbeoordelingsformulieren met de $410 \mathrm{VN}$-schaal over de voor iedereen verplichte algemene semi- 
artsstage (ASAS), de bijzondere (niet verplichte) semiartsstage (BSAS) en de wetenschappelijke stage van studenten uit het nieuwe curriculum, zijn vergeleken met de eindbeoordelingsformulieren van 70 studenten uit het oude curriculum over de coschappen interne geneeskunde, gynaecologie/obstetrie en huisartsgeneeskunde. De schaal op de beoordelingsformulieren van het oude curriculum kende vier waarden: $\mathrm{A}=$ excellent, boven het niveau van een coassistent in deze fase, $\mathrm{B}=$ adequaat, op het niveau van een coassistent van deze fase, $\mathrm{C}=$ voldoende, met enige aarzeling, de coassistent kan zich nog verbeteren op een aantal gebieden, en $\mathrm{D}=$ onvoldoende.

Tussentijdse beoordelingsformulieren zijn niet vergeleken, omdat deze wel in het nieuwe maar niet in het oude curriculum worden vastgelegd.

Ieder formulier bevatte meerdere te beoordelen kwaliteiten voor het oude curriculum (kennis en inzicht, houding, belangstelling, verantwoordelijkheidsgevoel, accuratesse, samenwerking, patiëntverslagen, technische vaardigheid) en voor het nieuwe curriculum (o.a. wijze van functioneren, professioneel gedrag, korte observaties, presentaties, patiëntverslagen).

\section{Resultaten}

Op elk formulier wordt voor meerdere onderwerpen een score gegeven. Van alle oordelen op de oud-curriculumformulieren betrof 46,6\% de score 'excellent', 52,8\% 'adequaat', 1,0\% 'voldoende' en 0,0\% 'onvoldoende'. Bij de beoordelingen in het nieuwe curriculum viel $38,7 \%$ van de oordelen in de categorie 'boven verwacht niveau', $61,2 \%$ in de groep 'verwacht niveau' en $0,42 \%$ in de groep 'onder verwacht niveau'. De figuren 1 en 2 geven de bevindingen weer bij 1567 scores (oud curriculum), respectievelijk 1358 scores (nieuw curriculum), uitgesplitst naar type stage.

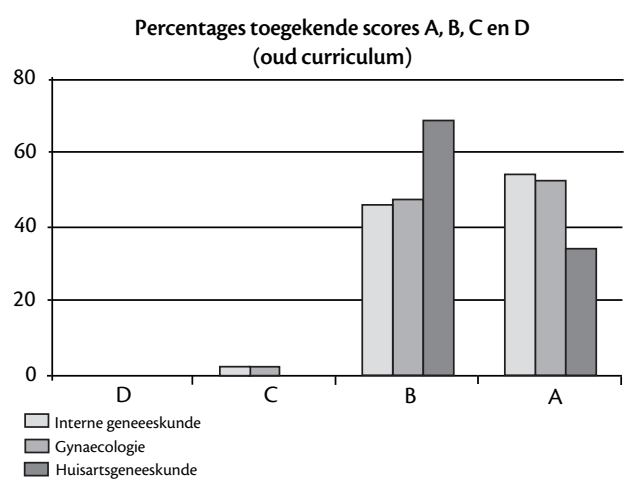

Figuur 1. Verdeling van 1567 toegekende scores bij oud-curriculumstudenten.

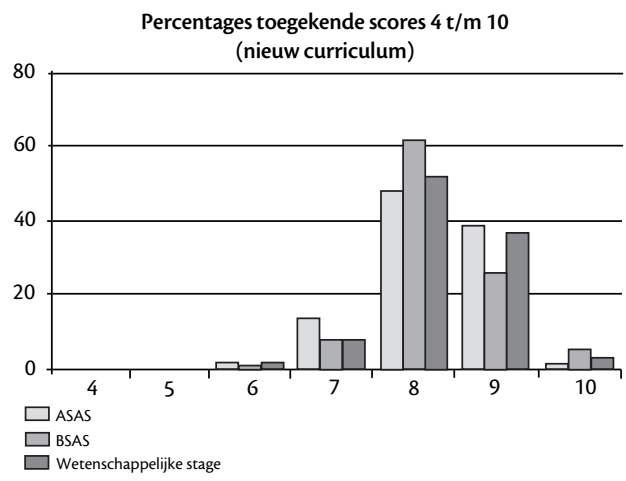

Figuur 2. Verdeling van 1358 toegekende scores bij nieuw-curriculumstudenten.

\section{Interpretatie}

Bij beide typen schalen worden weinig tot geen lage waarden toegekend. In het nieuwe curriculum wordt, met de 410VNschaal, wel relatief meer gescoord in de categorie 'verwacht niveau' dan in de categorie 'adequaat' bij het oude curriculum. De hoogste waarde 'excellent' wordt zeer vaak toegekend in het oude curriculum, vaker dan een score 10 of 9 in het nieuwe curriculum. Het statistisch toetsen van verschillen is lastig vanwege de verschillende betekenissen van de labels bij de waarderingen en omdat de stages niet dezelfde zijn, maar wanneer men alle scores $A$ versus $B+C$ van het oude curriculum vergelijkt met alle sco- 
res $9+10$ versus $6+7+8$, dan worden er meer hoge scores toegekend bij de letterschaal dan bij de 410VN-schaal (X2=9.46; df=1, $\mathrm{p}<0.01)$ De conclusie lijkt gerechtvaardigd dat in het algemeen iets lagere scores bij de nieuwe schaal worden toegekend.

\section{Discussie}

De $410 \mathrm{VN}$-schaal is ontwikkeld in de periode dat ook KKB's (mini-CEX) voor het onderwijs in de specialistenopleiding werden geïntroduceerd. ${ }^{7}$ De originele miniCEX-schaal (negen waarden met 1-3 als 'unsatisfactory', 4-6 als 'satisfactory' en 7-9 als 'superior') is inmiddels gereduceerd tot zes waarden en de schaalwaar $\neg$ deringen zijn aangepast in dezelfde richting als waarin ook de $410 \mathrm{VN}$-schaal is opgebouwd ('below expectations', 'meets expectations' en 'exceeds expectations', met toevoeging van een 'borderline'-categorie) ${ }^{8}$

Een bezwaar dat soms gevoeld wordt bij een dergelijke relatieve schaal, zoals de $410 \mathrm{VN}$, is dat de kandidaat geen progressie ziet en dat de beoordelaar geen progressie lijkt te kunnen weergeven, omdat het verwachte niveau meegroeit met de kandidaat. Dat probleem is niet wezenlijk, omdat gelijkblijvende scores over meerdere beoordelingen heen een vooruitgang weerspiegelen en een daling in score het ontbreken van progressie of een absolute daling van competentie impliceert.

De $410 \mathrm{VN}$-schaal is duidelijk geen volledige oplossing voor de relatief hoge scores. Ook hier wordt nog hoog gescoord, hoewel met meer gedetailleerde instructie dit wellicht verder geredresseerd kan worden. Hoge scores bij individuele beoordelingen zijn echter zoals gezegd een algemeen probleem. Ook de mini-CEX vertoont zelden lage scores: bij 1228 overall beoordelingen volgens de 9-puntsschaal werd bij slechts $2 \%$ lager dan 5 en bij 0,4\% lager dan 4 gescoord op de 9-puntsschaal. ${ }^{9}$
Er spelen meerdere factoren een rol bij de toekenning van deze scores, die de interpretatie van de bevindingen uit ons onderzoek beïnvloeden. Er is een mogelijk verschil in niveau van de twee groepen. De laatste jaarcohorten van het oude curriculum bevatten veel studenten die lang over de studie hebben gedaan; men mag verwachten dat dit een relatief minder goede groep studenten is. De eerste groep nieuw-curriculumstudenten zijn daarentegen uitsluitend nominaal studerenden die de langzamere studenten achter zich hebben gelaten. Tegen deze achtergrond mogen de bevindingen zeker worden geinterpreteerd als een bevestiging dat de 410VN-schaal een redelijker verdeling van scores oplevert dan het A-B-C-D-type schaal dat eerder is gebruikt. Ten slotte zij opgemerkt dat de scoringsaanwijzingen, zoals hierboven beschreven, op de formulieren van de nieuw-curriculumstudenten niet in deze vorm waren meegegeven. De aanwijzingen beperkten zich tot de formuleringen zoals aangegeven in tabel 1 .

Concluderend heeft de 410VN-schaal als voordeel boven andere schalen dat zij aansluit bij het denken in rapportcijfers. De schaal biedt echter meer houvast voor individuele beoordelingen dan alleen een 10-puntsschaal, omdat als start voor de beoordeling een middenwaarde wordt gekozen, en vervolgens afwijkingen worden afgewogen. Dat biedt meer kans op consistentie over beoordelingsmomenten bij dezelfde kandidaat, op gelijke normstelling over verschillende kandidaten bij dezelfde beoordelaar en op overeenstemming tussen beoordelaars. Ook biedt het meer beoordelingsgemak dan een schaal 1-3 of 0-3 of 1-5 die vaak behoefte geeft om tussenliggende halve waarden te scoren. De ervaringen met de schaal tot nu toe sterken ons in het gebruik ervan. 


\section{Dankwoord}

De auteurs danken mw. Geerte Slappendel voor de verzameling van de gegevens voor het onderzoeksgedeelte.

\section{Literatuur}

1. Albanese M. Rating educational quality: factors in the erosion of professional standards. Acad Med 1999;74(6):652-8.

2. Van der Vleuten CPM, Schuwirth LWT. Assessing professional competence: from methods to programmes. Med Educ 2005;39:309-17.

3. Norcini JJ. Work based assessment. BMJ 2003; 326: 753-5.

4. Cate ThJ ten, Bleker OP, Büller HA, Scherpbier AJJA. Opleiden van medisch specialisten - achtergronden en praktijk. 2nd ed. Houten: Bohn Stafleu van Loghum; 2005.

5. Fick ThE, editor. Trainingen voor de docent, 7: Competenties, toetsing en portfolio. Utrecht: Expertisecentrum voor Onderwijs en Opleiding UMC Utrecht; 2006.

6. Regehr G, MacRae H, Reznick RK, Szalay D. Comparing the psychometric properties of checklists and global rating scales for assessing performance on an OSCE-format examination. Acad Med 1998;73(9):993-7.
7. Norcini JJ, Blank LL, Duffy FD, Fortna GS. The Mini-CEX: a method for assessing clinical skills. Ann Intern Med 2003;138:476-81.

8. Norcini JJ. The Mini Clinical Evaluation Exercise (mini-CEX). The Clinical Teacher 2005;2(1)25-30.

9. Norcini JJ. MiniCEX [pre-conference workshop]. In: Programme and abstracts of the AMEE 2004 Conference; 5-8 september 2004; Edinburgh, UK.

De auteurs:

Prof. dr. Th.J. ten Cate is directeur van het Expertisecentrum voor Onderwijs en Opleiding van het UMC Utrecht.

Prof. dr. E.W.M.T ter Braak is internist-endocrinoloog en plaatsvervangend opleider Interne Geneeskunde in het UMC Utrecht.

Dr. J. Frenkel is kinderarts in het Wilhelmina Kinderziekenhuis van het UMC Utrecht.

Mw. A.C. van de Pol is semiarts bij de opleiding geneeskunde van de Universiteit Utrecht.

\section{Correspondentieadres:}

Prof. dr. Th.J. ten Cate, Expertisecentrum voor Onderwijs en Opleiding UMC Utrecht, Directie Onderwijs en Opleidingen, Universitair Medisch Centrum Utrecht, Postbus 85500, 3508 GA Utrecht, tel.: 030-2507010, t.j.tencate@umcutrecht.nl.

Belangenconflict: geen gemeld.

Financiële ondersteuning: geen gemeld.

\section{Summary}

At University Medical Centre Utrecht in 2004 a relative 4-10 Expected Level scale (410EL) was introduced for use in checklist assessments of senior clerks, such as MiniCEX assessments. The scale has advantages over other scales and could also be used in other face-to-face assessments. The method uses three ranges of scoring: below expectations (4 and 5), meets expectations (6, 7 and 8) and exceeds expectation (9 and 10). The basic assumption underpinning this method is that, in the absence of further information, students deserve a median score in the 'meets expectations' range of the scale. Information obtained while observing students can give assessors reason to decide that this score is too high or too low.

We describe the background and usage in practice of the 410EL scale. Our initial experiences with the new scale in clinical rotations compare favourably to those with the previous scale. (Ten Cate ThJ, Ter Braak EWTM, Frenkel J, Van de Pol A. The 4-to-10-expected-level scale for individual assessments. Dutch Journal of Medical Education 2006;25(4):157-163.) 